\title{
ANALISIS POTENSI KEBERLANJUTAN MULTI USAHA SUB SEKTOR PERIKANAN DI KABUPATEN SIDOARJO
}

\section{Analysis of Potential Sustainability of Multi Fisheries Sub Sector Business in the Sidoarjo Regency}

\author{
*Titis Istiqomah, M. Pudjihardjo, Sumarno dan Bagyo Yanuwiadi \\ Universitas Brawijaya Malang \\ Jl. Veteran, Ketawanggede, Kec. Lowokwaru, Kota Malang, Jawa Timur 65145, Indonesia \\ Diterima tanggal: 4 Desember 2018 Diterima setelah perbaikan: 8 Maret 2019 \\ Disetujui terbit: 26 Juni 2019
}

\begin{abstract}
ABSTRAK
Permasalahan sektor perikanan saling terkait antar sub sektor perikanan tangkap, budidaya, serta olahan dan pemasaran hasil perikanan. Penelitian bertujuan menganalisis potensi keberlanjutan usaha multi sub sektor perikanan skala kecil - menengah oleh masyarakat di Kabupaten Sidoarjo. Penelitian deskriptif dilaksanakan April $2015 \mathrm{~s} / \mathrm{d}$ April 2018. Survey terestris dengan teknik rekam data tertutup dan terarah menggunakan alat bantu kuesioner. Data diberi bobot dan dianalisa menggunakan analisis shift share dan statistik untuk mengetahui keterkaitan antar sub sektor perikanan terhadap potensi keberlanjutannya. Hasil analisis keberlanjutan usaha tangkap (kode 01.T) bernilai terendah 2,3529 gap 6,0 dari nilai tertinggi 8,3529. Nilai regresi usaha penangkapan ikan $Y=0,005+0,961 \mathrm{X}$ menunjukkan usaha penangkapan ikan belum mampu memberdayakan sektor lain. Tingkat signifikansi uji T tidak nyata $22,2 \%$. Nilai R Square 0,005 dan Adjusted R Square -0,061 merepresentasikan tingkat kepercayaan usaha penangkapan ikan sangat rendah. Keberlanjutan usaha perikanan budidaya di tambak (simbol 02.Y) bernilai terendah 2,9783. Nilai regresi linier sebesar $Y=0,980+3,375 \mathrm{X}$ menunjukkan usaha budidaya memberikan keberdayaan bagi sub sektor lain secara signifikan $97,8 \%$. Nilai R Square 0,225 dan Adjusted R Square 0,188 merepresentasikan keberlanjutan usaha budidaya kurang menjanjikan. Keberlanjutan olahan dan pemasaran hasil perikanan (kode 03.U) bernilai terendah 7,2600 dengan shift share gap positif 0,2600. Nilai regresi linier $Y=6,031+3,235 X$ signifikansi $100 \%$ menunjukkan usaha olahan dan pemasaran berpengaruh terhadap usaha lainnya, dengan nilai $R$ Square 0,651 dan nilai Adjusted R Square 0,636. Hasil penelitian menyimpulkan bahwa sub sektor olahan dan pemasaran hasil perikanan berpeluang besar untuk ditumbuh-kembangkan.
\end{abstract}

Kata Kunci: potensi keberlanjutan; usaha perikanan; olahan dan pemasaran; produk perikanan; sektor perikanan

\begin{abstract}
The problems of fisheries sector are interrelated between the capture fisheries, cultivation, processing and marketing of fishery products. The research aims to analyze the potential sustainability of small and medium scale multi sub-sector fisheries businesses by people in Sidoarjo Regency. Descriptive research was conducted from April 2015 to April 2018. Terrestrial survey with closed data recording techniques and questionnaires were used in the study. Data were measured and analyzed using shift share matrix and statistics to find out the relation between fisheries sub-sectors to their potential sustainability. Results of the capture business sustainability analysis (code 01.T) have the lowest value of 2.3529 gap 6.0 from the highest value of 8.3529. The regression value of fishing business $Y=0.005+0.961 X$ indicates that fishing businesses have not been able to empower other sectors. The significance level of the Ttest is not real $22.2 \%$. The $R$ Square value of 0.005 and Adjusted $R$ Square -0.061 represents the relatively low level of trust in fishing businesses. The sustainability of aquaculture business in the pond (symbol 02.Y) has the lowest value of 2.9783. The linear regression value of $Y=0.980+3.375 X$ indicates that cultivation provides empowerment for other sub-sectors significantly of $97.8 \%^{*}$. The value of $R$ Square 0.225 and Adjusted $R$ Square 0.188 representing the sustainability of aquaculture is less promising. Sustainability of processed and marketing of fishery products (code 03.U) has the lowest value of 7.2600 with a positive shift share gap of 0.2600 . The linear regression value $Y=6.031+3.235 X 100 \%$ significance indicates that the processed business and marketing affect other businesses, with the value of $R$ Square 0.651 and the value of Adjusted R Square 0.636. It is concluded that the processed and marketing of fishery products subsector have a great opportunity to be developed.
\end{abstract}

Keywords: sustainability potential; fisheries business; processed and marketing; fisheries product; fisheries sector 


\section{PENDAHULUAN}

Usaha perikanan di Kabupaten Sidoarjo dapat dibagi menjadi 3 sub sektor perikanan yaitu: (1) sub sektor perikanan tangkap, (2) sub sektor perikanan budi daya, serta (3) sub sektor olahan dan pemasaran hasil perikanan. Sub sektor perikanan tangkap diwujudkan dalam aktivitas nelayan di selat Madura dibayangi potensi konflik antar nelayan yang tinggi antara nelayan Sidoarjo dengan nelayan dari Kabupaten/Kota sekitarnya, akibat perebutan wilayah penangkapan ikan (fishing ground). Penelitian Hikmah (2008) mengenai analisis konflik nelayan di Selat Madura melaporkan bahwa telah terjadi 6 tipologi konflik yaitu: konflik kepemilikan sumber daya, konflik pengelolaan sumber daya, konflik cara produksi/ alat tangkap, konflik lingkungan, konflik usaha dan konflik primordial. Konflik yang terjadi cenderung terbuka dan bernuansa kekerasan karena dipicu oleh kondisi overfishing di perairan Selat Madura di sisi Barat.

Pemberdayaan ekonomi masyarakat pesisir di Kabupaten Sidoarjo sebenarnya dapat diarahkan untuk pemanfaatan tanaman mangrove sebagai bahan baku industri skala rumah tangga; untuk menekan potensi konflik. Keragaman mangrove secara empiris sangat kaya dan berpotensi untuk dikembangkan sebagai tanaman industri, namun belum dilakukan oleh Pemerintah setempat maupun stake holder lainnya (Istiqomah, 2018a). Potensi tamanan mangrove yang banyak sudah mulai dicoba untuk diolah dan dipasarkan oleh masyarakat secara mandiri (Bidayani, Soemarno, Harahab \& Rudianto). Hal ini sejalan dengan pendapat Mangkay, Harahab, Polii \& Soemarno (2013) yang menegaskan bahwa potensi ekosistem hutan mangrove mencerminkan peran mangrove.

Berbagai masalah dihadapi oleh masyarakat pesisir Sidoarjo sangat komplek. Wujud permasalahan terdapat di semua sektor perikanan. Pada sektor penangkapan; permasalahan mendasar yang sudah terjadi bertahun-tahun adalah kelebihan tangkap (over fishing) di Selat Madura sisi Barat. Selain itu, efek perubahan iklim (climate change) berpengaruh terhadap klimatologi harian dan bulanan di perairan laut Sidoarjo menyebabkan ketersediaan sumber daya ikan tidak dapat diprediksi. Hal ini menyebabkan usaha penangkapan ikan menghadapi kesenjangan kemungkinan yang besar (gambling).

Permasalahan perikanan budi daya berupa ancaman terhadap usaha pertambakan ikan dan udang di kawasan pesisir juga dibayangi oleh pencemaran, penyakit, dan benur atau bibit ikan yang tidak berkualitas. Air untuk budi daya adalah air payau yang merupakan pencampuran air laut (pasang surut) dengan air tawar dari sungai jelas membawa cemaran yang tidak bisa dihindari. Meskipun demikian, para petambak udang di Sidoarjo mampu membuktikan bahwa budi daya udang masih memungkinkan dilakukan dan produk hasil panennya bernilai ekspor, karena adanya pengakuan internasional terhadap budi daya menuju ke sistem organik ISO 65 IFOAM.

Pada sektor pengolahan hasil perikanan, produk turunan hasil pengolahan dibayangi oleh regulasi ekspor yang ketat (Pabrik krupuk udang diwajibkan menerapkan ISO 22000, OHSAS dan bahkan spesifik memiliki sertifikat BRC untuk bisa ekspor sesuai dengan persyaratan yang ditetapkan oleh 'Buyers' di Uni Eropa, Jepang dan Amerika sebagai pembeli utama krupuk udang Sidoarjo). Shofa dan Navastara, (2015) menyimpulkan adanya 3 (tiga) permasalahan utama dalam pengembangan industri pengolahan perikanan di Kabupaten Sidoarjo, yaitu: penggunaan teknologi yang sederhana, kemitraan usaha yang kurang, dan market share terbatas.

Berdasarkan permasalahan yang diungkapkan maka tujuan penelitian ini adalah untuk menganalisa potensi keberlanjutan usaha multi sub sektor perikanan skala kecil - menengah yang dilakukan oleh masyarakat di Kabupaten Sidoarjo.

Tempat penelitian di sentra kegiatan perikanan tangkap desa Banjarkemuning (kecamatan Sedati) dan desa Bluru Kidul (kecamatan Sidoarjo Kota), sentra perikanan budi daya di desa Sawohan (kecamatan Buduran) dan desa Tanjungsari (kecamatan Jabon), serta sentra olahan pemasaran hasil perikanan di desa Balongdowo (kecamatan Candi)dan desa Penatarsewu (kecamatan Tanggulangin). Penelitian dilaksanakan selama 3 tahun mulai April 2015 s/d April 2018.

Penelitian bersifat deskriptif data diperoleh melalui survey terestris. Jenis data yang digali selama penelitian adalah data kualitatif berupa pernyataan Responden yang di-kuantitatif-kan dengan pembobotan. Rekam data dilakukan dengan cara jajak pendapat yang digali secara diam-diam melalui percakapan sehari-hari yang terarah sesuai dengan kuesioner penelitian. 


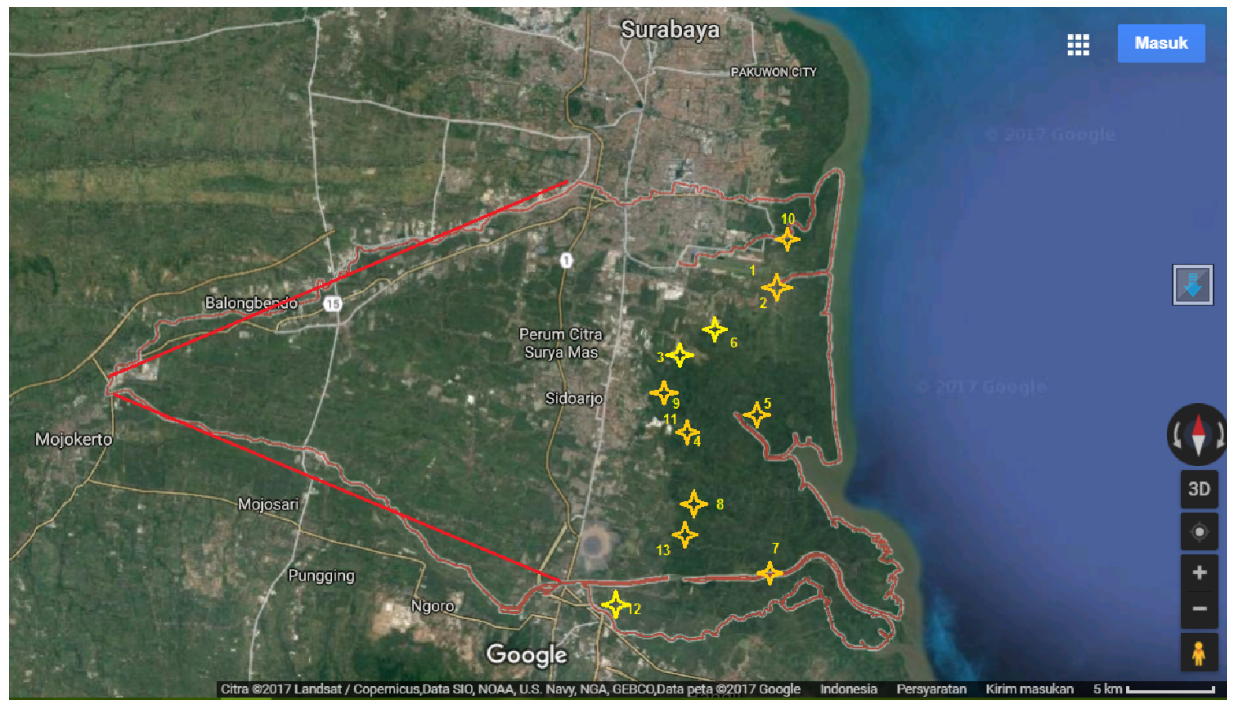

Gambar 1. Peta Lokasi Penelitian.

Figure 1. Map of the Research Location.

Responden dipilih secara sengaja (purposive sampling) dengan kriteria tertentu untuk memastikan tingkat kepercayaan atas jawaban dan pernyataan yang disampaikan jujur dan bermakna. Standar kompetensi masing-masing responden ditentukan terlebih dahulu sebelum pelaksanaan survey dengan bantuan informan. Kriteria kompetensi dasar adalah pengalaman responden dalam bidang usaha per sub sektor perikanan yang ditekuni oleh masing-masing sebanyak 100 orang responden terpilih minimal berpengalaman lebih dari 5 tahun berturut-turut.

Analisa data diawali dengan sortasi data ke dalam matriks shift share dan selanjutnya diberikan pembobotan. Teknik pembobotan diawali dengan merumuskan asumsi dalam bentuk deskripsi yang menggambarkan jawaban terbaik (skore 10) dan deskripsi jawaban terburuk (skore 1). Keterlibatan dan pengalaman Peneliti sebagai bagian dari komunitas masyarakat pesisir di Kabupaten Sidoarjo menentukan uraian asumsi dan kelaikan nilai pembobotan. Nilai bobot masing-masing yang diperoleh dari jawaban masing-masing responden dianalisis secara statistik menggunakan perangkat SPSS seri 2.3, untuk mengetahui makna hubungan hasil analisis masing-masing sub sektor perikanan terhadap potensi keberlanjutannya.

\section{KEBERLANJUTAN MULTI SUB SEKTOR PERIKANAN}

Keberlanjutan usaha multi sub sektor perikanan merupakan keniscayaan bagi masyarakat Kabupaten Sidoarjo, mengingat potensi unggulan wilayah di sektor ini sangat besar.
Peraturan Daerah Kabupaten Sidoarjo No. 6 Tahun 2009 tentang RTRW Kabupaten Sidoarjo Tahun 2009 - 2029 menempatkan kebijakan penetapan fungsi kawasan pesisir sebagai salah satu bagian yang penting. Hal tersebut memberikan ruang usaha yang cukup bagi masyarakat multi sub sektor perikanan untuk mengembangkan usahanya.

Hasil penelitian menunjukkan bahwa keberlanjutan multi sub sektor perikanan di Kabupaten Sidoarjo berbeda-beda antar sub sektor. Sub sektor perikanan tangkap dan sub sektor perikanan budi daya menghasilkan nilai rendah yang merepresentasikan potensi keberlanjutannya rendah apabila dibandingkan dengan sub sektor olahan dan pemasaran hasil perikanan. Sub sektor olahan dan pemasaran hasil perikanan memberikan peluang sangat besar untuk dikembangkan dan berkelanjutan. Hal ini disebabkan eksistensi Kabupaten Sidoarjo yang tumbuh pesat sebagai kawasan industri; memungkinkan ketersediaan bahan baku ikan untuk pengolahan dan pemasaran dapat 'didatangkan' dari sentra perikanan lain di Indonesia maupun impor; apabila hasil perikanan tangkap dan hasil produksi perikanan budi daya di Kabupaten Sidoarjo sendiri tidak mencukupi.

\section{Sub Sektor Perikanan Tangkap}

Militansi nelayan Sidoarjo dalam bekerja melakukan kegiatan penangkapan ikan sangat tinggi. Operasional kegiatan menangkap ikan dilakukan setiap hari sepanjang tahun, kecuali pada hari raya Keagamaan dan hari Jum'at. Libur tidak menangkap ikan umumnya tidak lebih dari 2 atau 3 hari saja; dan itu pun dilakukan secara bergantian 
di kalangan kelompok nelayan. Pergantian libur tersebut ditujukan untuk tetap memenuhi kebutuhan ikan bagi masyarakat Sidoarjo sendiri maupun kebutuhan para pengepul ikan untuk industri.

Kebiasaan nelayan yang melakukan kegiatan penangkapan ikan di Selat Madura pada umumnya melakukan kegiatan one day fishing, yaitu nelayan pergi dan pulang melaut dalam satu hari yang sama. Nelayan di perairan ini biasanya melaut saat sore hari sekitar pukul 15.00 - 17.00 WIB dan pulang pada pagi hari sekitar jam antara 03.00 - 06.00 WIB; atau berangkat pagi hari sekitar pukul 04.00 - 05.00 WIB dan pulang sore hari pukul 15.00 - 17.00 WIB (Soedrijanto. 2012). Lebih lanjut dijelaskan bahwa seluruh armada perahu penangkap ikan milik nelayan Sidoarjo adalah perahu kayu berkapasitas 5 GT kebawah. Terdapat usaha penangkapan ikan berkelompok untuk menangkap kerang-kerangan, ikan, dan udangudangan. Selain itu, terdapat perahu berkapasitas < 1 GT yang melakukan penangkapan ikan secara mandiri di pantai dan alur sungai yang dipengaruhi oleh pasang surut air laut.

Perairan sisi Barat Selat Madura merupakan kawasan yang subur bagi kehidupan ikan sepanjang tahun (Muhsonim \& Nuraini, 2006). Jenis-jenis ikan merupakan jenis ikan ekonomis penting meskipun nilai jualnya di pasar tidak begitu tinggi akan tetapi ketersediaan nya dilaut seringkali berubah ubah (Rostin, 2016). Hasil usaha penangkapan ikan yang terbesar di Kabupaten Sidoarjo adalah jenis kupang dan kekerangan. Ketersediaan sumber daya kupang dan kekerangan ini selalu tersedia sepanjang tahun, akibat cekaman pencemaran perairan laut di sisi Barat selat Madura yang menjadi muara sungai-sungai. Eksplorasi kekerangan berjalan seimbang dengan tingginya peningkatan sedimentasi di muara-muara sungai. Atmodjo (2011) menyatakan bahwa air sungai
Porong membawa angkutan sedimen yang terus menerus terakumulasi di muara.

Keberlanjutan usaha sub sektor perikanan tangkap (kode 01.T) memberikan nilai 2,3529 merupakan nilai terendah dengan gap 6,0 dari nilai tertinggi 8,3529. Nilai regresi usaha penangkapan ikan $Y=0,005+0,961 X$ menunjukkan keterkaitan satu usaha penangkapan ikan belum mampu memberdayakan sektor lain yang terkait dengan tingkat signifikansi uji $\mathrm{T}$ pada taraf tidak nyata $22,2 \%$. Nilai R Square 0,005 dan Adjusted R Square-0,061 (negatif) merepresentasikan bahwa tingkat kepercayaan masyarakat untuk melakukan / melanjutkan usaha di sektor penangkapan ikan sangat rendah.

Primyastanto, Efani, Soemarno \& Muhammad (2013) menyebutkan bahwa faktor-faktor yang berpengaruh nyata terhadap pengeluaran rumah tangga nelayan adalah pendapatan melaut, pendapatan non melaut, jumlah anggota keluarga dan tingkat pendidikan.

\section{Sub Sektor Perikanan Budi Daya}

Luas wilayah pesisir yang diidentikkan dengan mayoritas berupa areal pertambakan adalah 15,541,50 Hektar pada tahun 2010 atau $33,79 \%$ dari total luas wilayah Kabupaten Sidoarjo seluas 45,991,83 Hektar. Sebaran tambak terdapat pada 8 (delapan) Kecamatan masing-masing.

Fakta menunjukkan bahwa seluruh percabangan sungai menjadi anak sungai dan saluran-saluran air untuk pertambakan seluruhnya menanggung cemaran sampah maupun polutan pada aliran airnya. Padahal, air ini hampir merupakan satu-satunya sumber bahan baku air selain air sumur bor untuk kegiatan perikanan budidaya di kawasan pesisir yang menopang sumber kehidupan masyarakat pesisir.

Tabel 1. Sebaran Mangrove dan Tambak.

Table 1. Distribution of Mangrove and Ponds.

\begin{tabular}{clrrrrr}
\hline No & $\begin{array}{c}\text { Kecamatan/ } \\
\text { Sub district }\end{array}$ & $\begin{array}{c}\text { Mangrove/ } \\
\text { Mangroves }\end{array}$ & $\begin{array}{c}\text { Tambak/ } \\
\text { Ponds }\end{array}$ & $\begin{array}{r}\text { Luas Total/ } \\
\text { Total Area }\end{array}$ & $\begin{array}{c}\text { \% Mangrove/ } \\
\text { \% Mangroves }\end{array}$ & $\begin{array}{c}\text { \% Tambak/ } \\
\text { \% Ponds }\end{array}$ \\
\hline 1 & Waru & 148,44 & 438,00 & $2.424,00$ & 6,12 & 18,07 \\
2 & Sedati & 381,59 & $4.100,00$ & $7.313,00$ & 5,22 & 56,07 \\
3 & Buduran & 92,48 & $1.662,00$ & $3.240,00$ & 2,85 & 51,96 \\
4 & Sidoarjo Kota & 140,54 & $3.088,20$ & $5.856,83$ & 2,40 & 52,72 \\
5 & Candi & 138,74 & $1.031,00$ & $3.103,00$ & 4,47 & 33,23 \\
6 & Tanggulangin & 18,12 & 496,00 & $1.695,00$ & 1,07 & 29,26 \\
7 & Porong & 13,81 & 496,30 & $1.698,14$ & 0,81 & 29,22 \\
8 & Jabon & 302,70 & $4.230,00$ & $6.688,00$ & 4,53 & 63,25 \\
\hline & Jumlah/Total & $\mathbf{1 . 2 3 6 , 4 2}$ & $\mathbf{1 5 . 5 4 1 , 5 0}$ & & & \\
\hline
\end{tabular}


Kawasan perikanan budidaya di Kabupaten Sidoarjo terletak diantara kali Porong dan Kali Mas yang menjadi muara sungai Brantas. Terdapat banyak anak sungai kali Porong yang mengalir ke laut melalui wilayah perkotaan hingga pesisir Kabupaten Sidoarjo. Aliran anak sungai melintasi kawasan permukiman padat penduduk dan pertumbuhan industri yang terus berkembang pesat dari tahun ke tahun. Kenyataan ini menunjukkan bahwa potensi pencemaran yang harus 'ditanggung' oleh pesisir Kabupaten Sidoarjo sangat tinggi. Pencemaran disebabkan oleh akumulasi sampah dan buangan rumah tangga lainnya, limbah industri serta yang tidak kalah pentingnya adalah polutan an-organik dan lapisan minyak yang dibawa oleh air limpasan permukaan (run off) akibat presipitasi dan perkolasi air hujan.

Keberlanjutan usaha perikanan budidaya di tambak (simbol 02.Y) ditunjukkan oleh skor hasil analisis shift share 2,9783 merupakan skor terendah dalam komponen pendukung aktivitas usaha budidaya. Nilai regresi linier sebesar $Y=0,980+3,375 X$ menunjukkan bahwa usaha budidaya masih memberikan dampak keberdayaan bagi 3 sektor lain yang terkait dengan tingkat signifikansi uji $\mathrm{T}$ pada taraf nyata 97,8\%*. Nilai R Square 0,225 Adjusted R Square 0,188 merepresentasikan bahwa keberlanjutan usaha budidaya dianggap tidak menjanjikan oleh masyarakat para pelaku usahanya.

Fakta empiris menunjukkan bahwa umur budidaya udang yang menjadi acuan keberhasilan perikanan budidaya bagi para petambak; umumnya hanya mampu bertahan selama 60 - 70 hari di tambak. Petambak seringkali terpaksa memanen udang pada umur tersebut agar terhindar dari resiko kematian massal udang di tambak, yang berakibat merugikan para petambak. Guna mendorong keberlanjutan budidaya tambak, maka petambak secara pribadi maupun kelompok telah mencoba berbagai cara seperti: penanaman mangrove, pengerukan dasar tambak dan pengerukan alur sungai, mencoba berbagai probiotik, merekayasa proses budidaya, hingga mencoba membudidayakan berbagai jenis udang dan ikan lainnya dengan harapan untuk memperoleh hasil yang lebih baik.

Soedrijanto dan Istiqomah (2016) melaporkan bahwa budidaya udang windu di Sidoarjo pernah mencatat prestasi dunia dengan keberhasilan memperoleh sertifikat budidaya udang windu sistem organik ISP 65 IFOAM yang diterbitkan oleh lembaga sertifikasi ternama Natruland-Jerman tahun 2002 lalu, namun telah dicabut oleh Naturland akibat terjadinya bencana lumpur Lapindo tahun 2006.

\section{Sub Sektor Olahan dan Pemasaran Hasil Perikanan}

Hasil-hasil olahan perikanan yang sudah terkenal di pasaran, diproduksi secara turun temurun dan kemudian dikembangkan menjadi produk-produk olahan baru berbasis hasil perikanan oleh masyarakat pesisir di Kabupaten Sidoarjo antara lain disajikan pada Tabel 2. Penelitian Istiqomah, 2018b melaporkan bahwa produk olahan faktual yang ada di Kabupaten Sidoarjo sekaligus menjadi produk unggulan daerah, banyak digemari oleh masyarakat akan tetapi masih bersifat olahan tradisional sehingga perlu terus dikembangkan. Beberapa jenis produk telah mencapai pasar ekspor dengan regulasi yang sangat ketat ke manca negara.

Tabel 2. Produk Olahan dan Jangkauan Pemasarannya.

Table 2. Processing Products and Markets.

\begin{tabular}{cccc} 
No & $\begin{array}{c}\text { Hasil Perikanan/ } \\
\text { Fishery Products }\end{array}$ & \multicolumn{1}{c}{$\begin{array}{c}\text { Nama Produk Olahan/ } \\
\text { Name of Processed Products }\end{array}$} & $\begin{array}{c}\text { Jangkauan Pemasaran/ } \\
\text { Marketing Range }\end{array}$ \\
\hline 1 & Ikan bandeng/Milkfish & Bandeng asap/Smoked milkfish & Lokal, Nasional/Local, National \\
& & Bandeng tanpa duri/Boneless milkfish & Lokal/Local \\
Lokal/Local \\
\end{tabular}




\section{Lanjutan Tabel 2/Continue Table 2}

\begin{tabular}{|c|c|c|c|}
\hline No & $\begin{array}{l}\text { Hasil Perikanan/ } \\
\text { Fishery Products }\end{array}$ & $\begin{array}{c}\text { Nama Produk Olahan/ } \\
\text { Name of Processed Products }\end{array}$ & $\begin{array}{l}\text { Jangkauan Pemasaran/ } \\
\text { Marketing Range }\end{array}$ \\
\hline \multirow[t]{4}{*}{4} & \multirow{4}{*}{$\begin{array}{l}\text { Udang jerbung/Jerbung } \\
\text { shrimp }\end{array}$} & Terasi/Fish paste & Lokal, Ekspor/Local, Export \\
\hline & & Petis/Petis & Lokal, Ekspor/Local, Export \\
\hline & & Ebi/Dried ebi & Lokal, Ekspor/Local, Export \\
\hline & & Kerupuk/Crackers & Lokal, Ekspor/Local, Export \\
\hline \multirow[t]{3}{*}{5} & \multirow[t]{3}{*}{ Ikan cucut/Shark fish } & Sirip ikan/Fin fish & Ekspor/Export \\
\hline & & Daging ikan diasap/Smoked meat fish & Lokal/Local \\
\hline & & Daging ikan dibekukan/Frozen meat fish & Ekspor/Export \\
\hline 6 & Ikan pari/Stingray & Daging ikan panggang/Grilled meat fish & Lokal/Local \\
\hline \multirow[t]{3}{*}{7} & \multirow[t]{3}{*}{ Ikan belanak/Mullet fish } & Dikeringkan/Dried fish & Lokal, Nasional/Local, National \\
\hline & & Ikan segar/Fresh fish & Lokal/Local \\
\hline & & Dipedakan/Marinated fish & Lokal, Nasional/Local, National \\
\hline \multirow[t]{2}{*}{8} & \multirow[t]{2}{*}{ Ikan kakap/Red snapper fish } & Ikan segar (beku)/Fresh or frozen fish & Lokal, Ekspor/Local, Export \\
\hline & & Ikan kering/Dried fish & Lokal, Nasional/Local, National \\
\hline 9 & Ikan dorang/Dorang fish & Ikan segar (beku)/Fresh or frozen fish & Lokal, Ekspor / Local, Export \\
\hline \multirow[t]{2}{*}{10} & \multirow[t]{2}{*}{ Ikan gulamah/Croaker fish } & Ikan segar/Fresh fish & Lokal (pabrik surimi)* \\
\hline & & Kerupuk/Crackers & Lokal, Nasional/Local, National \\
\hline \multirow[t]{3}{*}{11} & \multirow[t]{3}{*}{ Ikan bawal/Pomfret fish } & Ikan segar (beku)/Fresh or frozen fish & $\begin{array}{l}\text { Bawal putih dan bawal bulan diekspor/ } \\
\text { White pomfret and Moon pomfret for } \\
\text { exports }\end{array}$ \\
\hline & & & $\begin{array}{l}\text { Bawal hitam pasaran lokal/Black } \\
\text { pomfret for local market }\end{array}$ \\
\hline & & Kerupuk/Crackers & Lokal, Nasional/Local, National \\
\hline 12 & Peperek/Peperek & Ikan kering (asin)/Dried fish (salted) & Lokal/Local \\
\hline \multirow[t]{3}{*}{13} & \multirow[t]{3}{*}{ Kerang/Mud clams } & Rebus (kupas)/Steam (without shell) & Lokal/Local \\
\hline & & $\begin{array}{l}\text { Segar/Fresh } \\
\text { Hidup/Life clams }\end{array}$ & $\begin{array}{l}\text { Lokal/Local } \\
\text { Regional (bibit kerang)/Regional (for } \\
\text { seedlings) }\end{array}$ \\
\hline & & Petis/Petis & Lokal, Ekspor/Local, export \\
\hline \multirow[t]{2}{*}{14} & \multirow[t]{2}{*}{ Kupang/Mud shells } & Rebus (kupas)/Steam (without shell) & Lokal/Local \\
\hline & & Kerupuk/Crackers & $\begin{array}{l}\text { Lokal, Nasional, Ekspor/Local, } \\
\text { National, Export }\end{array}$ \\
\hline \multirow[t]{2}{*}{15} & \multirow[t]{2}{*}{ Rumput laut/Seaweed } & Segar/Seaweed & Lokal/Local \\
\hline & & Kering/Dried seaweed & Lokal/Local \\
\hline
\end{tabular}

Keberlanjutan usaha pengolahan dan pemasaran hasil perikanan (kode 03.U) memperoleh nilai 7,2600 dengan shift share gap positif 0,2600 . Nilai regresi linier $Y=6,031+3,235$ $X$ dengan signifikansi uji T pada taraf sangat nyata $100 \%$ pada dasarnya menunjukkan bahwa usaha pengolahan dan pemasaran berpengaruh terhadap usaha lainnya yang dalam sub sektor terkait. Nilai $\mathrm{R}$ Square 0,651 dan nilai Adjusted $\mathrm{R}$ Square 0,636 menunjukkan bahwa berbagai macam jenis usaha olahan dan pemasaran hasil perikanan menjanjikan. Fakta empiris yang ditemukan di kalangan pengusaha olahan menyatakan bahwa bahan baku utama: 'ikan dan udang' maupun bahan pembantu selalu tersedia, dan mudah akses untuk memperolehnya meskipun dari luar pulau Jawa sekalipun. Pemasaran hasil perikanan produk olahan Sidoarjo dianggap mudah karena telah memiliki image yang kuat dibenak konsumen bahwa Sidoarjo merupakan sentra penghasil berbagai olahan hasil perikanan yang memiliki cita rasa tinggi.

\section{Kendala-Kendala yang Dihadapi Multi Sub Sektor Usaha Perikanan di Kabupaten Sidoarjo}

Pada Tabel 3 menjelaskan hasil analisis potensi keberlanjutan multi sub sektor usaha perikanan berdasarkan kendala yang dihadapi oleh para pelaku usaha sub sektor perikanan tangkap, sub sektor perikanan budidaya dan sub sektor olahan dan pemasaran hasil perikanan di Kabupaten Sidoarjo yang dirinci secara spesifik menyangkut kendala pada sumber daya alam, sumber daya manusia, beserta kebijakan-kebijakan di setiap kendala, berikut disajikan dalam bentuk tabel. 
Tabel 3. Kendala Masing-Masing Sub Sektor Perikanan. Table 3. Constraints of Each Fisheries Sub-Sector.

\begin{tabular}{|c|c|c|c|}
\hline $\begin{array}{l}\text { Permasalahan } / \\
\text { Problems }\end{array}$ & $\begin{array}{l}\text { Sub Sektor Perikanan } \\
\text { Tangkap/ Capture } \\
\text { Fisheries Sub-Sector }\end{array}$ & $\begin{array}{l}\text { Sub Sektor Perikanan Budi Dayal } \\
\text { Aquaculture Fisheries Sub-Sector }\end{array}$ & $\begin{array}{l}\text { Sub Sektor Olahan dan } \\
\text { Pemasaran/Processing and } \\
\text { Marketing Sub-Sector }\end{array}$ \\
\hline $\begin{array}{l}\text { Sumber Daya } \\
\text { Alam/Natural } \\
\text { resource }\end{array}$ & $\begin{array}{l}\text { 1. Ancaman overfishing / } \\
\text { Threat of overfishing } \\
\text { 2. Fishing base seluruhnya } \\
\text { berada di aliran } \\
\text { sungai (tidak langsung } \\
\text { menghadap kelaut } \\
\text { lepas), berpengaruh } \\
\text { terhadap kecepatan } \\
\text { dan efisiensi kinerja } \\
\text { penangkapan ikan; / The } \\
\text { fishing base is enttirely } \\
\text { in the river flow (not } \\
\text { directly facing the open } \\
\text { sea), affecting the speed } \\
\text { and efficiency of fishing } \\
\text { performance }\end{array}$ & $\begin{array}{l}\text { 1. Pencemaran / Pollution } \\
\text { 2. Perubahan kualitas tanah dan air yang semakin menurun / } \\
\text { Changes in the quality of land and water that are decreasing } \\
\text { 3. Belum termanfaatkannya sumberdaya mangrove sebagai } \\
\text { sumber industri pangan alternatif yang baru dengan baik / } \\
\text { The use of mangrove resources is not yet utilized as a new } \\
\text { alternative food industry source }\end{array}$ & $\begin{array}{l}\text { Sumber bahan baku lokal } \\
\text { bagi prosesor olahan produk } \\
\text { perikanan hingga aspek } \\
\text { pemasarannya belum tercukupi } \\
\text { dari hasil penangkapan } \\
\text { dan perikanan budidaya di } \\
\text { Kabupaten Sidoarjo sendiri / } \\
\text { Sources of local raw materials } \\
\text { for processors of processed } \\
\text { fishery products until the } \\
\text { marketing aspects have not } \\
\text { been fulfilled from the results } \\
\text { of fishing and aquaculture in } \\
\text { Sidoarjo Regency itself }\end{array}$ \\
\hline $\begin{array}{l}\text { Sumber Daya } \\
\text { Manusia } \\
\text { / human } \\
\text { resources }\end{array}$ & 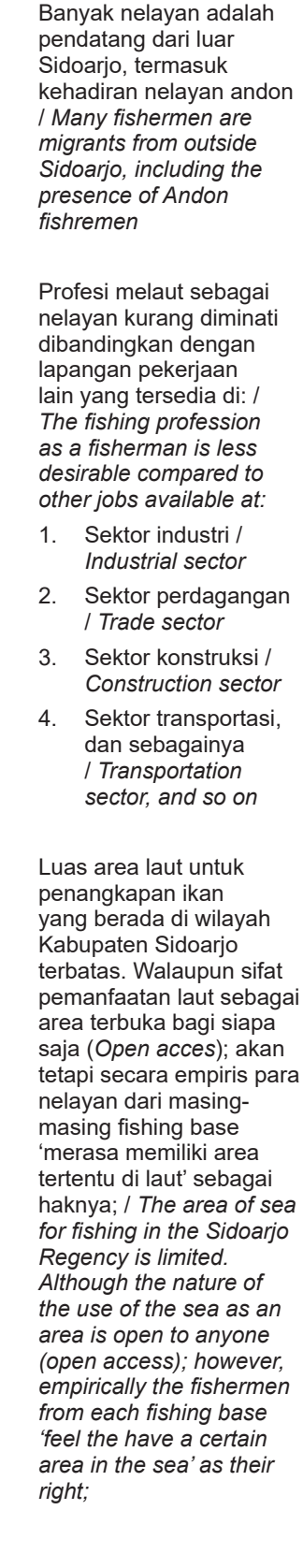 & 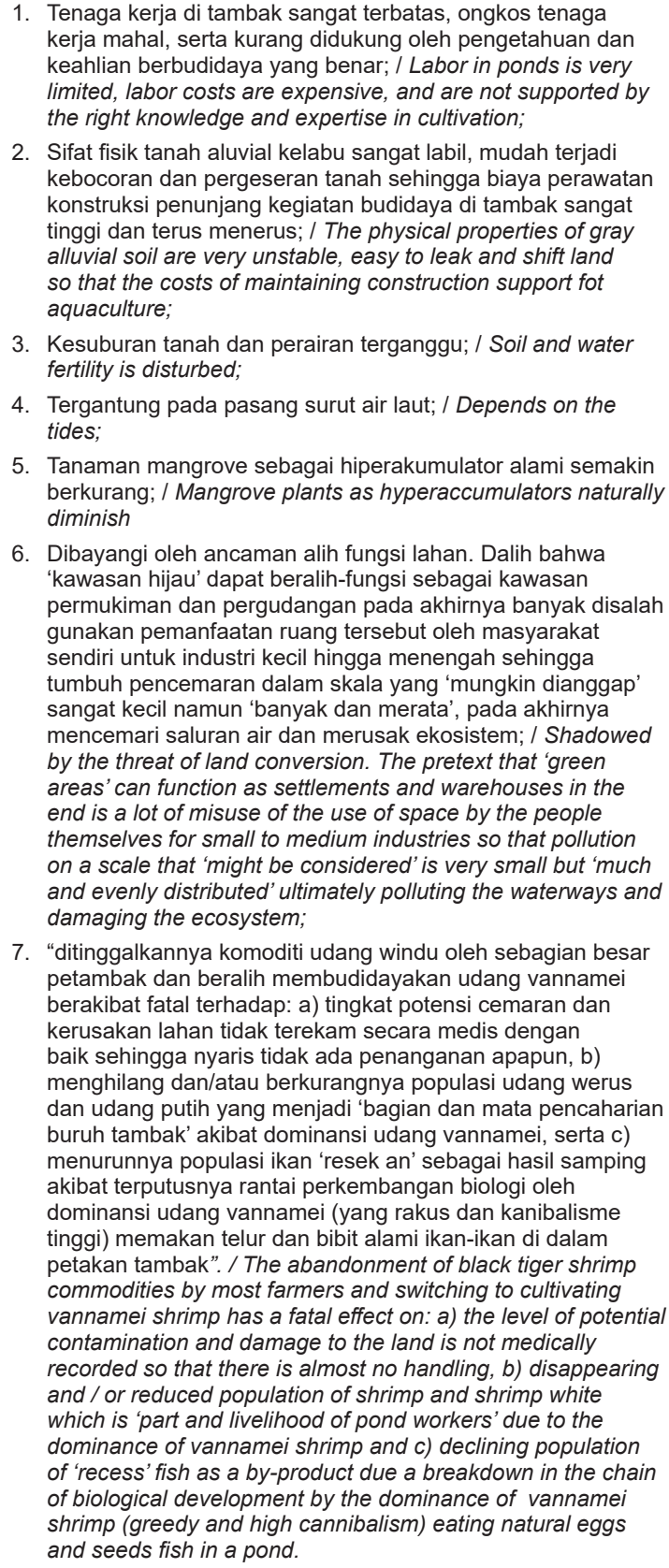 & $\begin{array}{l}\text { Belum ada pola pendampingan } \\
\text { oleh praktisi atau pendamping } \\
\text { profesional secara tuntas, } \\
\text { sehingga mayoritas masyarakat } \\
\text { pesisir hanya mampu mengolah } \\
\text { hasil perikanan akan tetapi } \\
\text { belum menguasai: / There is } \\
\text { has not been a complete pattern } \\
\text { of assistance by practitioners } \\
\text { of professional assistants, so } \\
\text { that the majority of coastal } \\
\text { communities are only able to } \\
\text { process fisheries products but } \\
\text { have not yet mastered them: } \\
\text { 1. Aspek manajemen } \\
\text { lingkungan yang } \\
\text { berkaitan dengan } \\
\text { kebersihan dan sanitasi } \\
\text { produk; / Environmental } \\
\text { management aspects } \\
\text { related to product hygiene } \\
\text { and sanitation; } \\
\text { Aspek sistem manajemen } \\
\text { mutu dan keamanan } \\
\text { pangan; / Aspects of quality } \\
\text { management and food } \\
\text { safety systems; } \\
\text { Aspek manajemen bisnis } \\
\text { yang lebih profesional bagi } \\
\text { keberlanjutan usahanya; / } \\
\text { A more professional } \\
\text { aspects of business } \\
\text { Aspek manajemen } \\
\text { pemasaran dan promosi; / } \\
\text { Marketing and promotion } \\
\text { management aspects }\end{array}$ \\
\hline
\end{tabular}


Lanjutan Tabel 3/Continue Table 3

\begin{tabular}{|c|c|c|c|}
\hline $\begin{array}{c}\text { Permasalahan/ } \\
\text { Problems }\end{array}$ & $\begin{array}{l}\text { Sub Sektor Perikanan } \\
\text { Tangkap/ Capture } \\
\text { Fisheries Sub-Sector }\end{array}$ & $\begin{array}{l}\text { Sub Sektor Perikanan Budi Daya/ } \\
\text { Aquaculture Fisheries Sub-Sector }\end{array}$ & $\begin{array}{l}\text { Sub Sektor Olahan dan } \\
\text { Pemasaran/Processing and } \\
\text { Marketing Sub-Sector }\end{array}$ \\
\hline \multirow[t]{2}{*}{$\begin{array}{l}\text { Kebijakan / } \\
\text { Policy }\end{array}$} & $\begin{array}{l}\text { Dibutuhkan payung hukum } \\
\text { yang lebih konkret untuk } \\
\text { mewujudkan daya saing } \\
\text { nelayan Kabupaten Sidoarjo } \\
\text { berupa landasan kebijakan } \\
\text { untuk: / A more concrete } \\
\text { legal umbrella is needed to } \\
\text { realize the competitiveness } \\
\text { of fishermen in Sidoarjo } \\
\text { Regency in the form of a } \\
\text { policy foundation for: } \\
\text { 1. Mengembangkan area } \\
\text { penangkapan ikan ke } \\
\text { perairan yang lebih } \\
\text { jauh (lebih dari one } \\
\text { day trip) bagi sebagian } \\
\text { nelayan Sidoarjo; / } \\
\text { Develop fishing areas } \\
\text { to further waters } \\
\text { (more than one day } \\
\text { trip) for some Sidoarjo } \\
\text { fishermen; } \\
\text { Meningkatkan } \\
\text { kapasitas dan daya } \\
\text { tangkap armada } \\
\text { penangkapan ikan; / } \\
\text { Increasing the capacity } \\
\text { and capture capacity of } \\
\text { fishing fleets; } \\
\text { Membekali nelayan } \\
\text { dengan basic safety } \\
\text { training; / Equip } \\
\text { fishermen with basic } \\
\text { safety training; } \\
\text { Membekali nelayan } \\
\text { dengan peralatan } \\
\text { bantu untuk } \\
\text { penangkapan ikan } \\
\text { seperti fish finder, } \\
\text { GPS dan sebagainya; } \\
\text { / Equip fishermen with } \\
\text { assistive equaipment } \\
\text { for fishing such as } \\
\text { fish finders, GPS and } \\
\text { so on; }\end{array}$ & $\begin{array}{l}\text { Perlu keterpaduan konkret dari eksekutif yang didukung } \\
\text { oleh legislatif dan yudikatif dalam rangka merumuskan serta } \\
\text { menerap-kembangkan: / It needs concrete integration from the } \\
\text { executive supported by the legislature and the judiciary in order } \\
\text { to formulate and develop: } \\
\text { 1. Kebijakan Pemerintah Kabupaten Sidoarjo yang lebih konkret } \\
\text { pro lingkungan, dengan didukung Peraturan Daerah yang } \\
\text { relevan agar kawasan 'hijau' tetap dapat dipertahankan dan } \\
\text { tidak beralih fungsi; / The Sidoarjo Regency Government's is } \\
\text { policy is more concrete, pro-environment, with the support of } \\
\text { relevant Regional Regulations so that the 'green' area can still } \\
\text { be maintained and not switch functions; } \\
\text { 2. Membuat Peraturan Daerah tentang sistem monitoring dan } \\
\text { evaluasi terhadap ijin-ijin usaha yang lebih bermanfaat, tepat } \\
\text { sasaran yang sesuai dengan kondisi di lapangan; / Making } \\
\text { Regional Regulations concerning the monitoring evaluation } \\
\text { system of business licenses that are more useful, right on } \\
\text { target that is in accordance with conditions in the field; } \\
\text { 3. Memperketat sistem manajemen supervisi penerapan } \\
\text { ijin tentang lingkungan mulai dari skala UKL-UPL hingga } \\
\text { Amdal; agar dipatuhi dengan sungguh-sungguh oleh para } \\
\text { pengusaha/investor; / Tightening the management system } \\
\text { to supersive the application of permits on the environment } \\
\text { starting from the UKL-UPL scale to Amdal; to be obeyed } \\
\text { seriously by entepreneurs / investors; } \\
\text { 4. Memperketat pengawasan terhadap penerapan ijin } \\
\text { usaha yang sudah beroperasi. Hal ini didasari maraknya } \\
\text { pemanfaatan kawasan permukiman dan pergudangan yang } \\
\text { justru digunakan sebagai tempat industri skala kecil hingga } \\
\text { menengah yang menghasilkan limbah dan pencemaran } \\
\text { lingkungan. Pengawasan terhadap aspek teknis usaha di } \\
\text { kawasan permukiman dan pergudangan merupakan hal } \\
\text { yang belum terlaksanakan; / Tightening supervision on } \\
\text { the implementation of business licenses that are already } \\
\text { operating. This is based on the widespread use of residential } \\
\text { and warehousing areas which are actually used as a place } \\
\text { for small to medium scale industries that produce waste and } \\
\text { environmental pollution. Supervision of technical aspects of } \\
\text { business in residential and warehousing areas is something } \\
\text { that has not been impemented; }\end{array}$ & $\begin{array}{l}\text { Dibutuhkan aturan teknis } \\
\text { berbasis payung hukum yang } \\
\text { ada untuk melaksanakan } \\
\text { lebih konkret program: / Legal } \\
\text { umbrella-based technical rules } \\
\text { are needed to implement more } \\
\text { concrete programs: } \\
\text { 1. } \quad \text { Pendampingan dari } \\
\text { profesional dan/atau } \\
\text { praktisi usaha yang } \\
\text { dilakukan secara tuntas, } \\
\text { intensif dan konsisten, } \\
\text { hingga tercapai indikator } \\
\text { keberhasilan usaha olahan } \\
\text { dan pemasaran hasil } \\
\text { perikanan; / Assistance } \\
\text { from professional and / or } \\
\text { business practitioners that } \\
\text { is carried out thoroughly, } \\
\text { intensively and consistently, } \\
\text { until indicators of success } \\
\text { of processed business } \\
\text { and marketing of fishery } \\
\text { products are achieved; } \\
\text { Mempermudah perijinan } \\
\text { dan/atau program bantuan } \\
\text { untuk kelengkapan } \\
\text { sertifikasi mutu pangan } \\
\text { (ISO, GMP, HACCP) } \\
\text { hingga pemenuhan syarat } \\
\text { dokumen mutu yang lebih } \\
\text { spesifik seperti: traceability, } \\
\text { ISO 8402, DS101 } \\
\text { dan BRC agar produk } \\
\text { terstandarisasi; sebagai } \\
\text { tindak lanjut kebijakan } \\
\text { sebelumnya berupa } \\
\text { kemudahan memperoleh } \\
\text { SIUPI; / Facilitate licensing } \\
\text { and / or assistance } \\
\text { programs for completing } \\
\text { food quality certification } \\
\text { (ISO, GMP, HACCP) to } \\
\text { fulfill more specific quality } \\
\text { document requirements } \\
\text { such as traceability, ISO } \\
\text { 8402, DS101 and BRC for } \\
\text { standardized products; as } \\
\text { a follow up to the previous } \\
\text { policy in the form of the } \\
\text { ease of obtaining SIUPI; }\end{array}$ \\
\hline & & & $\begin{array}{l}\text { 3. Menggandeng atau bekerja } \\
\text { sama dengan para pelaku } \\
\text { industri besar untuk turut } \\
\text { mengembangkan akses } \\
\text { pasar produk hasil UMKM } \\
\text { olahan hasil perikanan khas } \\
\text { Sidoarjo. / Cooperating } \\
\text { with or cooperating with } \\
\text { large industry players to } \\
\text { participate in developing } \\
\text { market access for products } \\
\text { produced by MSMEs } \\
\text { processed by fisheries } \\
\text { typical of Sidoarjo. }\end{array}$ \\
\hline
\end{tabular}

\section{PENUTUP}

Berdasarkan hasil penelitian disimpulkan bahwa potensi keberlanjutan usaha skala kecilmenengah pada sub sektor olahan dan pemasaran hasil perikanan di Kabupaten Sidoarjo memiliki peluang yang jauh lebih besar dibandingkan dengan sub sektor perikanan tangkap dan sub sektor perikanan budidaya.
Nilai analisis shift share keberlanjutan usaha sub sektor perikanan tangkap 2,3529 dengan regresi usaha penangkapan ikan $Y=0,005+0,961 X$ lebih rendah dibandingkan nilai analisis shift share sub sektor perikanan budi daya sebesar 2,9783 dengan regresi $Y=0,980+3,375 X$; serta nilai analisis shift share sub sektor olahan dan pemasaran hasil 
perikanan sebesar 7,2600 dengan regresi $Y=6,031+3,235 X$

Kebijakan implementasi yang perlu dlakukan adalah:

Pemerintah Kabupaten Sidoarjo perlu merancang stimulus pengembangan produk, standarisasi mutu, serta pengembangan jaringan pemasaran bagi usaha pengolahan hasil perikanan khas Sidoarjo agar semakin kuat bersaing dalam lingkup pasar yang lebih luas. Implementasi beberapa rekomendasi kebijakan dapat diwujudkan dalam bentuk:

a. Rancangan stimulus pengembangan produk; berupa pelatihan membuat produk baru disertai pembiayaan, uji organoleptik dan promosi selama 6 bulan hingga produk dikenal dan disukai masyarakat dan memiliki nilai ekonomi yang menguntungkan;

b. Standarisasi mutu; berupa bantuan insentif untuk sertifikasi produk, insentif melengkapi perijinan produk hingga produk dapat diterima sebagai produk komersial dengan perangkat hukum yang legal;

c. Pengembangan jaringan pemasaran; berupa fasilitasi dana dan program untuk pameran dan akses ke pemasaran berbasis internet selama beberapa bulan hingga produk telah benar-benar dikenal oleh khalayak luas sebagai produk baru;

Hal ini juga perlu diimbangi oleh sikap pro aktif eksekutif, legislatif dan yudikatif dalam implementasi Undang-Undang hingga peraturan teknis di masyarakat dan sektor usaha lainnya agar sumber daya alam tetap terjaga kelestariannya. Implementasi peraturan teknis yang perlu dibuat sebagai payung hukum usaha olahan dan pemasaran hasil perikanan antara lain: Peraturan Daerah penetapan kawasan konservasi yang terintegrasi sebagai kawasan usaha berkelanjutan antara sub sektor perikanan tangkap, perikanan budidaya dan olahan hasil perikanan; melalui kajian ilmiah dari SKPD terkait.

UMKM olahan dan pemasaran hasil perikanan juga masih membutuhkan dukungan bahan baku dari sub sektor penangkapan ikan dan sub sektor perikanan budidaya; oleh karena itu kedua sub sektor pendukung tersebut perlu fasilitasi Pemerintah untuk perbaikan manajemen sumber daya pada masing-masing sub sektor; agar aktivitas usaha dapat tetap bertahan dalam jangka panjang.

\section{UCAPAN TERIMA KASIH}

Penulis mengucapkan terima kasih kepada Iwan Hamzah, SE.; tokoh masyarakat petambak Sidoarjo dan Agus Triono, S.Pi., penyuluh perikanan Kabupaten Sidoarjo; atas peran membantu Peneliti bertemu dengan tokoh-tokoh kunci masyarakat pesisir Kabupaten Sidoarjo di berbagai sub sektor perikanan.

\section{DAFTAR PUSTAKA}

Atmodjo, W. (2011). Studi Penyebaran Sedimen Tersuspensi di Muara Sungai Porong Kabupaten Pasuruan. Buletin Oseanografi Marina. Edisi Oktober 2011.

Badan Pusat Statistik (BPS). (2016). Statistik Daerah Kabupaten Sidoarjo. Badan Pusat Statistik Kota Sidoarjo.

Bidayani, E., Soemarno, Harahab, N. \& Rudianto. (2016). Implementation of Blue Economy Concept as The Efforts of Mangrove Resource Conservation in Sidoarjo Coastal Area, East Java, Indonesia. International Journal of Ecosystem, 6(2): 25-34. DOI: 10.5923/j.ije.20160602.01.

Hikmah, Z. (2008). Analisis Konflik Nelayan Dalam Pengelolaan Sumber daya Perikanan Selat Madura Dalam Perspektif Sosiologis Hukum (Studi Kasus Nelayan Batah Kecamatan Kwanyar, Kabupaten Bangkalan, Provinsi Jawa Timur). Program Studi Manajemen Bisnis dan Ekonomi Perikanan Kelautan. IPB. Bogor.

Istiqomah, T. (2016). Ishikawa Effect Rancang Bangun Biodiversitas Pesisir. Seminar Nasional Biodiversitas VI, Surabaya 3 September 2016. F-MIPA Universitas Airlangga. Surabaya.

Istiqomah, T. (2018a). Karakterisasi Ekonomi Pesisir Kabupaten Sidoarjo Berbasis Pengkayaan Keragaman Mangrove. Agrikan. Jurnal Universitas Muhammadiyah Ternate. IOSR Journal Of Environmental Science, Toxicology and Food Technology (IOSR-JESTFT). E-ISSN: 2319-2402.

Istiqomah, T. (2018b). Analisis Gender Peran Wanita Sebagai Stimulator Ekonomi Keluarga Nelayan di Pesisir Kabupaten Sidoarjo. Fish Scientiae. Jurnal IImu-ilmu Perikanan dan Kelautan, Vol. 8 No. 1 Juni 2018. ISSN: 1693-3710.

Mangkay, S. D., Harahab, N., Polii, B. \& Soemarno. (2013). Economic Valuation of Mangrove Forest Ecosystem in Tatapaan, South Minahasa Indonesia. IOSR Journal Of Environmental Science, Toxicology And Food Technology (IOSR-JESTFT) e-ISSN: 2319-2402,p- ISSN: 2319-2399. Volume 5, Issue 6 (Sep. - Oct. 2013), PP 51-57. 
Muhsonim, F.F., \& Nuraini, C. (2006). Kajian Tingkat Pemanfaatan Sumber daya Ikan di Perairan Selat Madura Dengan Menggunakan Metode Holistik Serta Analisis Ekonominya. Jurnal Protein, Vol. 13 No. 1. Tahun 2013.

Peraturan Daerah Kabupaten Sidoarjo No. 6 Tahun 2009. Rencana Tata Ruang Wilayah Kabupaten Sidoarjo Tahun 2009 - 2029.

Primyastanto, M., Efani A., Soemarno \& Muhammad, S. (2013). Faktor yang Berpengaruh Terhadap Pendapatan dan Pengeluaran Nelayan Payang Jurung di Selat Madura. Wacana, Vol. 16, No. 1 (2013). ISSN: 1411-0199 E-ISSN: 2338-1884.

Rostin. (2016). The Effect of Economic Empowerment of the Coastal Communities and Social Capital on Coastal Community Welfare. The International Journal Of Engineering And Science (IJES). Volume 5 Issue 2 Pages PP 12-16. ISSN (e): 2319 - 1813 ISSN (p): 2319 - 1805.

Soedrijanto, A., \& Istiqomah, T. (2016). Organic Black Tiger Shrimp Farming System (ISO 65 IFOAM): Strategy Through Open Spirit Reap Back to Nature. Journal of Aquaculture \& Marine Biology, DOI: 10.15406/jamb.2016.04.00069

Shofa, S.U. \& Navastara, A.M. (2015). Faktor Penentu Pengembangan Industri Pengolahan Perikanan Di Kabupaten Sidoarjo melalui Pengembangan Ekonomi Lokal. Jurnal Teknik, ITS Vol. 4, No. 2, (2015) ISSN:2337-3539 (2301-9271 Print). Perencanaan Wilayah dan Kota, Fakultas Teknik Sipil dan Perencanaan ITS Surabaya.

Soedrijanto, A. (2012). Analisis Kawasan Konservasi Pesisir di Kabupaten Sidoarjo. Dinas Perikanan dan Kelautan Kabupaten Sidoarjo. 